\title{
“E se essa Criança for Gay?": Heteronormatividade e Homoparentalidade em Cena
}

\author{
"Y si ese Niño es Gay?": Heteronormatividad y Homoparentalidad en Escena
}

"What if this Child were Gay?": Heteronormativity and Homoparentality on the Stage

\author{
Lívia Lima Gurgel \\ ORCID: https:/orcid.org/0000-0003-2095-2415 \\ Universidade do Estado do Rio de Janeiro, Rio de Janeiro/Brasil
}

Anna Paula Uziel

ORCID: https://orcid.org/0000-0001-7807-3910

Universidade do Estado do Rio de Janeiro, Rio de Janeiro/Brasil

Declaração de Direito Autoral

A submissão de originais para este periódico implica na transferência, pelos autores, dos direitos de publicação impressa e digital. Os direitos autorais para os artigos publicados são do autor, com direitos do periódico sobre a primeira publicação. Os autores somente poderão utilizar os mesmos resultados em outras publicações indicando claramente este periódico como o meio da publicação original. Em virtude de sermos um periódico de acesso aberto, permite-se o uso gratuito dos artigos em aplicações educacionais e científicas desde que citada a fonte conforme a licença CC-BY da Creative Commons.

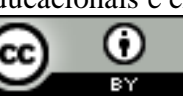

Creative Commons Atribuição 4.0 Internacional.

\section{Resumo}

O presente artigo traz o recorte de uma pesquisa que tem como tema a adoção por casais homossexuais em Fortaleza. Compreende-se a existência de uma multiplicidade de possibilidades familiares, e entre elas estão as famílias formadas por casais de pessoas do mesmo sexo que buscam tornar-se pais e mães através da adoção. Neste recorte são apresentadas algumas ideias sobre a vivência de pais e mães homossexuais que constituem famílias que fogem aos modelos hegemônicos, mas que se encontram atravessadas pela heteronormatividade que impera na sociedade. Foram realizadas entrevistas com oito casais de Fortaleza, em uma pesquisa cartográfica, através da qual se buscou acompanhar os processos vivenciados pelas pessoas entrevistadas. As narrativas compartilhadas pelos casais que participaram da pesquisa apontam para diferentes escolhas quando se trata de dialogar ou não com as crianças adotadas sobre a homossexualidade dos pais e das mães que as adotaram. Também trazem receios de que a criança adotada seja homossexual e que os pais e mães adotivas sejam culpabilizadas por isso. Reflete-se sobre a pluralidade de estratégias utilizadas por essas famílias e sobre a importância de pensarmos acerca das possíveis relações existentes entre a orientação sexual dos pais e das mães e a sexualidade de crianças e adolescentes que crescem em famílias que destoam dos modelos hegemônicos sem que esta relação seja necessariamente posta como negativa ou problemática.

Palavras-chaves: Homoparentalidade; Adoção; Famílias; Homossexualidade.

\section{Resumen}

El presente artículo trae el recorte de una investigación que tiene como tema la adopción por parejas homosexuales en Fortaleza. Se comprende la existencia de una multiplicidad de posibilidades familiares, y entre ellas están las familias formadas por parejas de personas del mismo sexo que buscan convertirse en padres y madres a través de la adopción. En este recorte se presentan algunas ideas sobre la vivencia de padres y madres homosexuales que constituyen familias que huyen a los modelos hegemónicos, pero que se encuentran atravesadas por la heteronormatividad que impera en 
la sociedad. Se realizaron entrevistas con ocho parejas de Fortaleza, en una investigación cartográfica, a través de la cual se buscó acompañar los procesos vivenciados por las personas entrevistadas. Las narrativas compartidas por las parejas que participaron en la investigación apuntan a diferentes opciones cuando se trata de dialogar o no con los niños adoptados sobre la homosexualidad de los padres y de las madres. También traen temores de que el niño adoptado sea homosexual y que los padres y madres adoptivas reciban la culpa por ello. Se reflexiona sobre la pluralidad de estrategias utilizadas por esas familias y sobre la importancia de pensar sobre las posibles relaciones existentes entre la orientación sexual de los padres y las madres y la sexualidad de niños y adolescentes que crecen en familias que se alejan de los modelos hegemónicos sin que esta relación sea necesariamente puesta como negativa o problemática.

Palabras claves: Homoparentalidad; Adopción; Familias; Homosexualidad.

\begin{abstract}
The present article brings up the cut of a research that has as its theme the adoption by homosexual couples in Fortaleza. It is understood that there is a multiplicity of family possibilities, and among them are families formed by same-sex couples who seek to become fathers and mothers through adoption. Thus, some ideas about the experience of homosexual mothers and fathers are presented, which are families that escape the hegemonic models, but its have a affect by the heteronormativity that prevails in society. Interviews were made with eight couples from Fortaleza, in a cartographic research, through which the processes experienced by the persons interviewed were monitored. The narratives shared by the couples who participated in the research indicate to different choices when it comes to dialoguing or not with the adopted children about the homosexuality of the parents who adopted them. They also raise fears that the adopted child be homosexual and the foster parents could be blamed for it. It reflects on the plurality of strategies used by these families and on the importance of thinking about the possible relations between the sexual orientation of the parents and children and adolescents who grow up in families that contrast from the hegemonic models without this relation be necessarily seen as negative or problematic.
\end{abstract}

Keywords: Homoparentality; Adoption; Families; Homosexuality.

\section{Introdução}

As famílias se apresentam como instituições que atravessam os mais diversos contextos sócio-históricos, estando presentes em diferentes sociedades e culturas. Seus significados variam, podendo ser amplos ou restritos, relacionados a vínculos sanguíneos, afetivos ou a ambos, incluindo apenas modelos hegemônicos ou também aqueles que destoam desses últimos. Pensar sobre essa instituição possibilita que realizemos uma análise sobre as transformações pelas quais ela vem passando ao longo do tempo, para que possamos acompanhar as atuais possibilidades de configurações familiares existentes em nossa sociedade e refletir sobre como essa sociedade vem se posicionando diante de tais configurações. Alguns debates giram em torno do questionamento: estaria a família chegando ao fim? Mudanças recentes no Brasil, como a decisão tomada pelo Supremo Tribunal Federal em 2011, que reconhece a união estável entre pessoas do mesmo sexo, trouxeram essa discussão novamente à tona, colocando no centro do debate as famílias formadas por casais do mesmo sexo, que são nomeadas como famílias homoparentais. O termo homoparentalidade foi traduzido do francês homoparentalité, que surgiu em 1997 e foi criado pela Association des parents et futurs parents gays et lesbiens (APGL) (Uziel, 2007). A utilização do termo ganhou uma função estratégica, na medida em que nomeia uma forma de parentalidade (ou dimensão dela) até então sem nomeação, colocando-a em evidência. Ainda hoje podemos encontrar 
debates sobre a utilização ou não do termo para nos referirmos a casais homossexuais com filhas ${ }^{1}$, uma vez que, em alguma medida, o termo associa a orientação sexual dos pais e mães à parentalidade exercida por elas.

Apesar de a homossexualidade não ser mais considerada como uma doença, como já previam o Código Internacional de Doenças (CID) desde 1990, e o Manual de Diagnóstico e Estatístico de Transtornos Mentais (DSM), desde 1973, existe ainda um aparato de normas que busca regular e orientar corpos e sexualidades a partir da heterossexualidade. Warner (1993, citado por Junqueira, 2012), refere que a heteronormatividade institui a heterossexualidade, pensada quase sempre no singular, como aponta Junqueira (2012), como única possibilidade de expressões identitárias e sexuais, a única natural e legítima, colocando para as homossexualidades o lugar de desvio, crime, aberração, pecado, perversão, imoralidade e assim por diante. A heteronormatividade, segundo aponta Junqueira (2012), se relaciona com a produção e a regulação de subjetividades e relações sociais, mais do que a homofobia, porém também associada a ela.

Silva, Uziel e De Garay Hernández (2013) se referem à família como instituição dinâmica e que sofre o impacto de transformações sociais, políticas e econômicas, ao mesmo tempo em que também produz tais transformações, ganhando novos contornos ao longo dos tempos. Além da chamada "família tradicional" - monogâmica e heterocentrista - são cada vez mais visíveis em

\footnotetext{
${ }^{1}$ Considerando a proposta de construir um trabalho que dialoga com as questões sobre gênero e orientações sexuais que fogem à norma, ao invés de apresentar categorias mistas de pessoas utilizando o masculino, será utilizado o feminino. Essa se apresenta como uma possibilidade para chamar a atenção para a utilização do masculino na generalização das categorias humanas. Torna-se possível também, a partir da escrita deste trabalho, apresentar uma linguagem em que as marcas de gênero estejam menos presentes. Apenas quando estivermos nos referindo a participantes/autores homens utilizaremos o masculino, ou no caso em que são apresentadas citações diretas em que o masculino é utilizado pelas autoras.
}

nossa sociedade diferentes tipos de organizações familiares, como as famílias formadas por casais de pessoas do mesmo sexo com ou sem filhas. O fato de uma diversidade de famílias ter mais visibilidade em nossa sociedade e aos poucos ser mais possível falar delas, não significa, entretanto, que são socialmente aceitas. (Silva, Uziel \& De Garay Hernández, 2013).

Essas possibilidades familiares nos colocam diante da necessidade de desconstruir algumas certezas que parecem naturalizadas. Butler (2003, p. 224) refere que

Variações no parentesco que se
afastem de formas diádicas de família
heterossexual garantidas pelo
juramento do casamento, além de
serem consideradas perigosas para as
crianças, colocam em risco as leis
consideradas naturais e culturais que
supostamente amparam a
inteligibilidade humana.

Considerando esse contexto em que algumas decisões no cenário Brasil parecem atuar no sentido de possibilitar um caminho na direção da conquista de direitos para casais homossexuais, como a já referida decisão do Supremo Tribunal Federal, assim como a decisão tomada pelo Conselho Nacional de Justiça, em 2013, segundo a qual foi proibido que os cartórios se negassem à habilitação, celebração de casamento civil ou de conversão de união estável em casamento entre pessoas de mesmo sexo, mas sem deixar de considerar que esse é um campo constantemente atravessado por tensões, marcado por tentativas de retrocesso, o que se relaciona também à heteronormatividade atuante em nossa sociedade, foi desenvolvido um estudo voltado para a temática da adoção por casais homossexuais na cidade de Fortaleza.

A decisão do STF se apresenta como um importante marco a ser considerado no contexto nacional e também se relaciona à questão da adoção. Coitinho-Filho e Rinaldi (2015, p. 291) explicam que a decisão do Supremo Tribunal Federal, que "reconheceu a 
união de homossexuais como entidade familiar e merecedora de proteção do regime jurídico de união estável", trouxe o reconhecimento de um quarto modelo de família na sociedade brasileira, aquela que se origina a partir da união entre pessoas do mesmo sexo. Anteriormente, a partir da Constituição Federal, três configurações familiares eram reconhecidas como legítimas: a decorrente de casamento, da união estável ou a monoparental (onde há uma pessoa com filhas). Com relação à adoção, explicam que, anteriormente à decisão do STF, só poderiam pleitear conjuntamente uma filiação adotiva, pessoas casadas civilmente ou em união estável. Logo, pares homossexuais poderiam encontrar dificuldades para adotar conjuntamente uma criança ou adolescente, apesar de que algumas decisões favoráveis eram tomadas em âmbito jurídico. Entretanto, o posicionamento do STF trouxe maior segurança para esses casais, que antes dependiam do entendimento dos Juízes (Coitinho-Filho \& Rinaldi, 2015).

Pensando também no contexto brasileiro, em que é possível observar um crescente conservadorismo e uma ampliação da legitimação de discursos de ódio direcionados a pessoas LGBT, a construção do trabalho se deu, também, como forma de posicionamento político diante de tais posturas discriminatórias e disseminadoras de ódio. Conversar com as famílias participantes, acompanhá-las e pesquisarCOM ${ }^{2}$ (Moraes, 2010) elas se apresentam como possibilidade de resistência em meio a um contexto de intolerâncias.

\section{A pesquisa cartográfica}

A pesquisa foi realizada a partir da cartografia, pesquisa-intervenção que permite pensar a pesquisa como um campo que se mostra a partir dos olhares e das vivências das

\footnotetext{
2 Como refere Moraes (2010), a expressão "PesquisarCOM" diz respeito a uma prática que se faz não sobre o outro, mas com o outro, que ganha espaço e passa a ser visto como colaborador na formulação de questões, na construção da pesquisa e do conhecimento.
}

pessoas entrevistadas, considerando esses sujeitos como ativos e potentes na construção da pesquisa. Considerando "o objetivo principal da cartografia de pesquisar a experiência, entendida como o plano no qual os processos a serem investigados efetivamente se realizam" (Tedesco, Sade \& Caliman, 2013, p. 300), foi possível trabalhar com entrevistas na cartografia. As autoras nos ajudaram a pensar como as entrevistas permitem que acompanhemos os movimentos e rupturas que podemos encontrar nas falas de nossas participantes, além de permitirem intervenções e a catalisação de momentos de passagem. Atentas ao fato de que a experiência é o principal objetivo da entrevista, pensamos este método como ferramenta de acesso ao "plano compartilhado de experiência" (Tedesco, Sade \& Caliman, 2013 , p. 300). Trabalhamos também com a perspectiva do "PesquisarCOM", que diz respeito a um pesquisar que se faz com o outro sujeito e não sobre ele, uma vez que o outro não é mais visto como um sujeito qualquer e sim como expert, que também contribui na formulação de questões, e todas contribuem e se envolvem nos processos de transformações. "O pesquisar com o outro implica uma concepção de pesquisa que é engajada, situada. Pesquisar é engajar-se no jogo da política ontológica. Que realidades produzimos com nossas pesquisas?" (Moraes, 2010, p. 42).

Durante a preparação inicial para a pesquisa $^{3}$, esta foi submetida e aprovada pelo Comitê de Ética da Universidade ${ }^{4}$, através da Plataforma Brasil, e foi preparado o Termo de Consentimento Livre e Esclarecido (TCLE) para todas as participantes ${ }^{5}$. Para encontrar os casais que colaboraram com o estudo foram utilizadas diversas estratégias, que incluíram contatos com pessoas próximas que pudessem indicar possíveis participantes, e-mails para

\footnotetext{
${ }^{3} \mathrm{O}$ trabalho foi realizado com apoio da Coordenação de Aperfeiçoamento de Pessoal de Nível Superior - Brasil (CAPES), através de uma bolsa de mestrado.

${ }^{4}$ CAAE: 80489917.9.0000.5282

5 Todos os nomes de participantes utilizados nesse trabalho são fictícios.
} 
instituições que trabalham com pessoas LGBT, Grupos de Apoio a Adoção, entre outras. Ao todo foram realizadas 10 entrevistas, com oito casais (dois casais foram entrevistados duas vezes), sendo quatro casais de lésbicas e quatro de gays, que se encontravam em momentos distintos com relação à adoção: alguns haviam adotado há anos, outros estavam em processo de vinculação com a criança que seria adotada, outros estavam realizando o processo de avaliação pela equipe judiciária. Em cada encontro, antes do início de nossas entrevistas, nos apresentávamos, eu explicava o propósito da pesquisa, como se daria aquele encontro, e o TCLE era entregue e lido por cada participante. Após esse momento, o TCLE era assinado e tinha início a entrevista, após a autorização ou não para a gravação da mesma. As entrevistas tiveram durações variadas, desde encontro de 50min a outros em que permaneci com o casal por cerca de $5 \mathrm{~h}$. Além disso, foram realizadas em diferentes locais, como restaurante, shopping e na casa dos casais entrevistados, por exemplo.

\section{Sobre a homossexualidade de pais e mães: entre o dito e não dito}

Zambrano (2008) discute a possibilidade de uma criança adotada por homossexuais sofrer estigmatizações ao longo de sua vida, quando se revelar ter sido adotada por dois pais ou duas mães. Rogério (45) narrou uma experiência vivenciada por sua filha, Amanda (8), que se articula ao que é apontado pela autora.

Assim, na escola, por exemplo, estivemos fazendo a matrícula $e$ aparentemente não houve nenhuma dificuldade, mas a gente sente certa dificuldade dos professores, mais assim "como que lida com isso" ... Eu percebo nos coleguinhas, que ela criou uma relação, até outro dia ela chegou triste, reclamando de umas brincadeiras, e eu já conhecia alguns comentários de uns meninozinhos que reproduzem os padrões homofóbicos talvez dos pais. (ROGÉRIO).
Em função dessa possibilidade iminente, as famílias encontram formas de enfrentamento, que podem ser diversas, e entre elas podemos encontrar a não revelação acerca da orientação sexual dos pais e das mães (Zambrano, 2008). As estratégias utilizadas pelas famílias que participaram dessa pesquisa variam e, em alguns casos, a opção escolhida foi não falar sobre a homossexualidade. Algumas entrevistadas explicaram que não houve um momento em que explicaram para a criança adotada que ela seria filha de duas mães ou dois pais, até mesmo pela inexistência dessa explicação quando se trata de um pai e de uma mãe heterossexuais. Tereza (55, mãe de Rafael, 4) relatou uma situação que a surpreendeu:

Há um mês atrás o Rafael (4) me surpreendeu. Eu estava fazendo um trabalho de campo e a Manuela ficou no carro com ele, enquanto eu visitava as pessoas. Aí um amigo nosso que estava lá perguntou "Rafael, tu quer trocar uma das tuas duas mães por mim, pra eu ser teu pai?" Aí ele disse: "Não, obrigada. Desculpe, não preciso de um pai, eu já tenho duas mães".

Manuela (35) explicou que não haviam conversado com o filho sobre ele ter duas mães: "Foi naturalmente, assim como a criança identifica que tem o pai e a mãe, naturalmente. Na verdade ele sabe que tem duas mães, sabe o nome delas, aí ele sabe, identificou em casa". Tereza complementou o relato, pontuando que "Ele apresenta a gente assim pros amigos: essa é minha mãe Manuela, essa é minha mãe Tereza, ele nunca teve problema de falar isso".

Maíra (32, mãe de Gabriel, 4, e Diego, 9) também trouxe um relato nessa direção:

Quando eles foram receber a gente, $a$ moça do serviço social disse que seriam duas mães, a única coisa que tivemos que ajustar é que seriam duas mães, aí eles chamam de mãe Maíra e mãe Beatriz, mas a gente 
nunca precisou conversar, não tinha como esconder, era ele olhar pra frente e ver duas mães, a gente disse que não tinha nenhum pai, a gente nunca deixou de ser carinhosa e de se beijar, se abraçar na frente deles, não há nenhuma questão disso, mas é um processo tão natural, é que nem você querer dizer pra uma criança que você adota assim: você tem um pai e uma mãe, você não faz isso, a criança tá vendo. Eu não tenho o que dizer, então foi bem nesse sentido.

Para alguns casais, portanto, não parece ser necessário explicar para as crianças ou adolescentes adotadas que suas famílias terão uma composição diferente de outras famílias. Consideram que essa percepção se dá de forma natural, a partir do convívio, e que essas crianças não trazem grandes questionamentos ao constatar a presença de duas mães ou de dois pais. Porém, existem outras possibilidades elegidas por alguns casais que participaram da pesquisa, que optam por dialogar com as filhas sobre o fato de serem uma família formada a partir de um casal homossexual.

Então, nós nos colocamos à mesa, falamos "Olha, Bia, dois pais que vivem juntos, existe a família $X, a$ família $Y$, isso não quer dizer que nós somos felizes ou infelizes, a gente vive e você vai começar a perceber se nós somos felizes ou infelizes e tudo vai ser decidido em grupo, nós três. Sua família é essa, seus dois pais, nós somos casados, e isso existe na sociedade". (FELIPE).

Temos medo do preconceito. Você já viu um vídeo ${ }^{6}$ que viralizou no facebook, eu acho que é até da Espanha, de uma menina... O meu medo é aquele, questionarem por que ela tem dois pais. É isso que eu quero

\footnotetext{
${ }^{6}$ https://www.cmjornal.pt/mundo/detalhe/meninaemociona-internet-ao-defender-colega-que-tem-doispais
}

ensinar pra ela desde pequena, assim uns cinco anos, explicar pra ela o que é, por que, pra ela saber, pra ela ter apoio, quando questionarem "por que tu tem dois pais?", ela saber dizer por isso, por isso e por isso. (ELIAS).

Inclusive, num primeiro momento que fomos falar das regras pra ela, mostrei a família, que iam ter pessoas que iam perguntar, como agora uma coleguinha aqui perguntou "cadê tua mãe?". Ai perguntou se eu era pai dela, e o outro, eu expliquei: somos dois pais. Aí enfim, eu mostrei um papelzinho pra ela e pedi pra ela identificar, tinham várias famílias, pai solteiro, mãe solteira, dois pais, homem e mulher, e tinha um casal homoafetivo com um menino, não com uma menina. Aí perguntei qual parecia mais com a gente e ela disse que era o de dois homens com um menino. Eu disse: família é onde tem amor, não importa se é homem com homem, homem e mulher... Ela não conversa muito ainda, a gente pergunta se ela tá feliz, se ela se sente segura. Ela ainda fica muito calada. (ROGÉRIO).

Um elemento chama a atenção. Aquelas famílias que optaram por não conversar com as filhas sobre a homossexualidade são formadas por casais de lésbicas, ou seja, essas crianças passam a ter duas mães. A figura materna, bastante naturalizada como aquela que cuida e dá afeto, muitas vezes é também a única presente em famílias heterossexuais, quando ocorrem divórcios, por exemplo, e a criança fica sob responsabilidade da mãe. Queremos sugerir, com isso, que a presença de duas mães pode causar menos estranheza do que a presença de dois pais, pelas relações construídas socialmente em torno da mulher e da maternidade. O homem é visto, de maneira geral, como provedor financeiro, como tendo características mais relacionadas à virilidade $\mathrm{e}$ 
à dureza, o que o tornaria menos capaz de cuidar plenamente de crianças sem a ajuda de uma figura feminina e, talvez por isso, esses pais se sintam mais seguros promovendo um diálogo com as crianças adotadas, para que elas entendam suas realidades familiares, que podem ser alvo de estigmas e discursos moralizantes e discriminatórios. A revelação parece ser uma forma buscada por esses casais para ajudar a criança a compreender que a realidade em que ela está inserida pode ser considerada normal, sem a necessidade de ser escondida, para que ela se fortaleça e tenha possibilidades de enfrentar e defender a si mesma e a sua família quando for necessário.

De Garay Hernández e Caetano (2015) trouxeram um estudo sobre filhas de famílias formadas por mães lésbicas e consideram que

Es importante el diálogo entre madres e hijas, justamente para que ejerciten un pensamiento que promueva la pluralidad y multiplicidad de formas de ser y de relacionarse, para que entiendan los propios procesos relacionales dentro del grupo familiar y de donde históricamente viene la discriminación (De Garay Hernández \& Caetano, 2015, p. 122).

Não se trata de afirmar que em famílias formadas por lésbicas não haverá estranhamento ou questionamentos e que quando existirem pais gays a sociedade trará mais discriminações, não é uma regra, não há pré-determinação. Assim como não existe uma forma única de lidar com a questão, como nos apontam os relatos das entrevistadas. As narrativas nos trazem que não necessariamente é preciso haver um momento de explicação e diálogo com a criança ou adolescente para que ela entenda ou não vivencie um estranhamento com relação a sua configuração familiar ser formada por dois pais ou duas mães e que as estratégias utilizadas pelas famílias são variadas. Algumas podem se sentir mais seguras ou confortáveis ao proporcionarem um momento de diálogo franco com a criança, acreditando que isso pode ajudar no fortalecimento da filha para enfrentar possíveis estigmatizações ou discriminações. Outras famílias não optam por esse momento em que são feitos esclarecimentos, acreditando que não é uma etapa necessária. Existe, portanto, uma pluralidade de possibilidades que podem ser vivenciadas por essas famílias, que também são plurais e múltiplas.

\section{Um encontro entre a homoparentalidade e a heteronormatividade}

Vilhena, Souza, Uziel, Zamora e Novaes (2011) afirmam que, apesar das famílias formadas por casais homossexuais não serem novas formas de famílias, a homossexualidade continua se tornando assunto quando aparece, uma vez que a heteronormatividade atravessa os olhares das pessoas. Portanto, ainda que não haja impeditivos legais para que um casal homossexual adote uma criança ou adolescente, a homossexualidade é posta em pauta por inúmeros sujeitos, como aqueles que compõem as equipes técnicas, as operadoras de direito ou pela sociedade em geral, como as famílias, colegas de trabalho, entre outros. Uziel (2007) refere que a orientação sexual dos pais e das mães pode ser tematizada de diferentes formas, por exemplo, quando surge o temor de que a inexistência dos dois sexos traga algum transtorno de desenvolvimento psicológico para as crianças, ou quando são utilizados argumentos que afirmam que a orientação sexual dos pais e das mães pode influenciar a sexualidade das filhas, ou até mesmo pelo risco de sofrer abuso sexual ao qual as crianças estariam expostas por serem adotadas por casais homossexuais. Outro argumento diz respeito ao direito de submeter a criança a mais preconceitos por ser uma criança adotada por dois homens ou duas mulheres.

De Garay Hernández (2013) defende que muitos discursos heteronormativos podem ser reforçados por mães lésbicas (assim como por pais gays), que escondem a sua sexualidade das filhas. O medo de que as próprias filhas cometam discriminações ou sejam discriminadas por terem duas mães ou dois pais e o receio de que as filhas sejam 
homossexuais aparecem entre as razões pelas quais a sexualidade pode ser escondida.

Ao longo das entrevistas realizadas nessa pesquisa, tanto Lucas (31) e Rogério (45) como Maíra (32) e Beatriz (32) se referiram aos receios de que, por serem casais homossexuais, acabem influenciando a orientação sexual das crianças adotadas por elas ${ }^{7}$.

Mas sabe o que me preocupa nessa questão de ser um casal de mulheres? Mais uma coisa: o tal do e se essa criança for gay? Será que foi uma coisa que a gente causou, algo que a gente influenciou? Não, não, se nasce com ela... Isso nos preocupa... (BEATRIZ).

\section{E se acontecer? (PESQUISADORA).}

A gente não saberia se a referencia dela foi nós como casal gay ou se isso era inato a ela... (MAÍRA).

Eu digo algo pra mim mesma pra eu me tranquilizar com relação a isso, ainda assim vai ser uma escolha dela... Que bom que ela teve liberdade de escolha! [...] Minha preocupação é que ela não se sinta presa a esse modelo ou a modelo nenhum. (BEATRIZ).

Eu acho que não tem como não influenciar de alguma maneira, mas não ao ponto dele dizer "vou ser gay porque minhas mães são gays", não... mas não tem como... [...] Mas acho que em algum momento ele vai chegar a uma idade em que ele seja capaz de fazer as próprias escolhas. $O$ que queremos colocar não é A ou $B$ como certo ou errado, mas que ele

\footnotetext{
${ }^{7}$ Cabe explicitar que esse receio não está estritamente relacionado ao cenário adotivo. Homens e mulheres que tiveram filhas biológicas, a partir de relacionamentos heterossexuais, e que passam a se relacionar com pessoas do mesmo sexo também podem apresentar este receio.
}

seja capaz de avaliar isso. (BEATRIZ).

Lucas e Rogério contaram que há algum tempo sentiam receio e muita resistência para adotar um menino por conta da ideia difundida socialmente sobre a criança ser influenciada pela sexualidade dos pais. Outro fator que gerava preocupação para o casal era a possibilidade de a criança adotada sofrer mais preconceito por ser adotada por dois homens. Meletti e Scorsolini-Comin (2015) também encontraram essas preocupações na pesquisa que realizaram, na qual as participantes do estudo apresentavam preocupações relacionadas ao que a sociedade pensa sobre a parentalidade exercida por casais homossexuais e sobre os possíveis sofrimentos aos quais as crianças poderiam ser expostas por terem pais gays e mães lésbicas. Também expressaram temor pelas ideias de que pais e mães homossexuais influenciam a orientação sexual das filhas. No estudo de Meletti e Scorsolini-Comin, inclusive, apesar de as participantes terem o desejo de serem pais ou mães, as dificuldades vislumbradas agiram no sentido de que a concretização da parentalidade fosse adiada. Rogério e Lucas narraram que refletiram bastante sobre as inseguranças que estavam sentindo $\mathrm{e}$ perceberam que seus receios eram reflexos de diversas construções sociais sobre a parentalidade gay e que eles estavam sendo influenciados por tais construções quando temiam um futuro preconceito que a filha poderia passar caso se descobrisse homossexual ou a culpa que poderiam receber pela orientação sexual da criança adotada.

De Garay Hernández (2013) refere que tais receios são compreensíveis, uma vez que esses pais e essas mães tiveram vidas atravessadas por discriminações, porém criam uma sensação de que a família tem menos valor, obstaculizando a construção de uma percepção de diferenças como geradoras de riquezas.

Outro elemento apresentado por Rogério e Lucas esteve relacionado ao medo de adotar um menino por conta da ideia que 
existe na sociedade sobre o abuso sexual ser cometido, na maioria das vezes, por homens homossexuais, então sentiam-se receosos, acreditando que poderiam relacioná-los a abusadores sexuais. Meletti e ScorsoliniComin (2015) consideram que esses receios se colocam como dificuldades para pais e mães homossexuais que buscam a parentalidade, pois temem que a criança se torne depositária de preconceitos que são voltados à orientação sexual dos pais ou mães. Um dos questionamentos apresentados pelos casais foi com relação a como explicar para a criança adotada que ela tem dois pais ou duas mães. $\mathrm{O}$ apoio psicológico foi apontado como imprescindível para a criança compreender a família da qual faz parte.

Para Lucas e Rogério, a participação no Grupo de Apoio a Adoção os ajudou a desconstruir os receios que sentiam e possibilitou ao casal ampliar o perfil da criança para incluir crianças do sexo masculino. Porém, em um segundo encontro com os dois, Rogério relatou uma situação que havia sido vivenciada havia pouco tempo na escola de Amanda (filha adotada pelo casal, 11 anos) e que mostrou que esses temores ainda estavam presentes para o casal.

Outro dia, por exemplo, eu cheguei e a menina que pega ela na escola disse assim, olhe tem um bilhete da professora, disse que ela passou o dia reclamando, que tava assadinha, com dor na genitália, aí me bateu logo aquela nóia. Eu chamei ela, perguntei que conversa era aquela... Ela tinha dito pra professora que desde ontem estava com a mesma calcinha, na hora eu me preocupei mais com a história da assadura, que ela poderia estar com alguma coisa, alguma doença. [...] Aí depois fui entender a história da calcinha, eu disse "Amanda, vem cá..." Porque ela ainda faz xixi na cama, toda noite ela acorda, quando faz xixi, aí bate na porta do quarto, eu levanto, troco ela e coloco ela pra dormir de novo. Aí eu disse: hoje tu não fez xixi? Ai ela: fiz... Aí eu disse: então assim, você trocou calcinha de madrugada quando levantou. Quando você foi pra aula de manha, papai deu banho $e$ trocou a calcinha, então você trocou a calcinha duas vezes, como você falou na escola que não trocou? Aí bateu logo aquela angústia, os fantasmas que a gente cria. Vão pensar que a gente tá sendo negligente, ou sei lá, ela dizendo que tá com dor na genitália, se não vão imaginar que estamos abusando dessa criança...

Dantas e Ferreira (2015) realizaram uma pesquisa com um casal homossexual em Goiânia e apontaram que os entrevistados expuseram uma preocupação em não incentivar práticas homossexuais nas crianças adotadas, também apontando o receio de cair sobre eles a responsabilização pela orientação sexual das mesmas. Um dos participantes verbalizou, inclusive, que tece elogios a mulheres bonitas na frente dos filhos, mas não elogia homens para não parecer que está incentivando os filhos. O comportamento de elogiar mulheres é esperado dos homens socialmente e esse casal estaria, portanto, buscando seguir uma norma social (Dantas \& Ferreira, 2015). Caso agissem elogiando homens, poderia ser considerado como um desvio à norma corrente, a heteronorma, que, mesmo com relação a casais homossexuais, continua agindo e impondo modos de existir, buscando regular corpos, sexualidades e comportamentos.

Ao longo das entrevistas realizadas, entretanto, esse receio não se apresentou de forma unânime ou homogênea. Manuela (35) afirmou que nunca se questionou sobre o assunto, enquanto sua companheira, Tereza (55), relatou que já teve essa preocupação.

Já, já me questionei... O Rafael, ele brinca com brinquedos de menino, mas ele brinca muito com meninas. Aí eu me perguntava... (TEREZA). 
Mas isso aí é totalmente natural. (MANUELA).

Tu acha que é natural. Mas eu tenho dúvidas. Ai eu pergunto "Filha, isso é normal?" Aí ela diz claro que é normal mãe. (TEREZA).

Isso fica na nossa cabeça pelo fato das pessoas já criarem isso! Entendeu? Ele pode ser gay ou não ser, isso aí vai depender dele. (MANUELA).

E se ele for não tem problema nenhum. (TEREZA).

Felipe (46) e Marcos (46) afirmaram que esse questionamento nunca partiu deles, mas que outras pessoas apresentavam essa preocupação.

As pessoas falaram. Inclusive meu irmão disse: que tipo de criação você vai dar pra essa menina? Ela vai ser sapatão quando crescer? Eu respondi: eu não sei, eu não sei nem se as suas vão ser, se seus filhos vão ser. (FELIPE).

Ele perguntava: você sabe o que sua filha vai ser quando crescer? (MARCOS).

Pois é, e eu dizia [...] Eu não sei, não tenho como prever futuro, eu sei que ela vai ser muito bem criada, porque a mesma criação que eu recebi e o Marcos recebeu, nós vamos tentar repassar. Então se eu conseguir repassar pelo menos $10 \%$ do que eu recebi e o Marcos, conjuntamente, tenho certeza que a menina vai ser uma boa pessoa, respeitando as pessoas, vivendo a vida dela feliz. (FELIPE).

Leandro (52) e Erick (41), outro casal entrevistado, relataram que não percebiam essa preocupação de forma consciente, mas eram cautelosos quando estavam com os filhos, evitavam se beijar na frente de
Henrique (12) e Leo (10), considerando que este comportamento poderia estar relacionado a tais receios.

Então uma vez conversando com essa amiga, a gente disse que a gente não se beija na frente deles. Aí ela disse "O que? O Henrique vai ter que ver vocês abraçados, beijo, não precisa ser beijo sexual não". Aí ela foi logo em cima do negócio. Ela disse " $E$ vocês sabem que a orientação sexual deles não tem absolutamente nada a ver com a orientação sexual de vocês". Porque no fundo ela desconfiava que isso era responder a um discurso moralista, sacana, que os pais heterossexuais não orientam a sexualidade dos seus filhos, tanto é que podem virar gays, mas que os gays orientam né? Enfim... Isso não passava pela nossa cabeça, mas é como se essa nossa escolha fosse por isso. O fato é que quando ela diz isso, a gente ficou achando doidisse nossa, aí começamos a namorar na frente deles, deitar junto, enfim.

Ao longo das entrevistas, outros elementos foram apresentados, como o que foi relatado por Antônio (29), que se preocupa com a possibilidade de que Laura (10 meses) se descubra lésbica e tenha medo de que os pais sejam culpabilizados, o que poderia evitar que a filha vivenciasse sua sexualidade da forma que desejasse. Nesse caso, o receio não residia em influenciar a orientação sexual de Laura, mas de que, caso Laura se descubra lésbica, tenha receio de ser quem ela é, para que a família não sofra mais discriminação.

Já pensei sobre isso, mas no caso da nossa filha. Tem um seriado, o "13 reasons why", que tem um caso de uma menina que tem pais gays, e ela se descobre lésbica, só que ela não quer dizer pros outros, tenta se reprimir, porque ela sofre tanto preconceito que ela não queria ter mais um na família pra sofrer isso... Aí eu pensei assim, se a Laura for 
lésbica, será que ela vai se sentir culpada? Ah, porque vão dizer que ela é lésbica porque os pais são gays, então ela vai ficar se martirizando... Vão dizer que ela é gay, pelos pais serem gays. Minha preocupação é ela se martirizar, se sentir culpada, não ser quem ela é por medo de preconceito se acharem que isso é culpa nossa. (ANTÔNIO).

A preocupação de Antônio está relacionada tanto com o desejo de que a filha possa viver e expressar sua orientação sexual da maneira que assim desejar, como também com a orientação sexual dele e do seu companheiro, Elias (28), pois pensam que, socialmente, pode ser feita uma correlação entre as orientações sexuais dos pais e da filha, o que seria visto como negativo socialmente, uma vez que haveria culpabilizações. Quando Maíra e Beatriz estavam em processo de vinculação com dois irmãos, Gabriel (4) e Diego (9), foi possível conversar com elas pela segunda vez, pois anteriormente havíamos conversado durante o processo de avaliação pela equipe judiciária. Maíra falou novamente $\mathrm{o}$ assunto, referindo que

A sexualidade deles em si quanto pessoa a gente nem sabe o que vai ser pra frente. A gente ainda vai se descobrir nessa questão, a gente se preocupa como se por algum motivo eles se descubram homossexuais, as pessoas não digam que eles foram contaminados, induzidos, e que ele tenha maturidade pra entender que em nenhum momento poderia ter sido algum resquício disso. Mas que foi uma coisa inerente a ele, a vontade de estar com sexo $A$ ou $B$ não há motivação externa a isso, é uma coisa que nasce com ele e aflora. Pode acontecer ou não, então vamos saber.

Esse aspecto relacionado à homoparentalidade, em que são feitos questionamentos sobre a possível influência da orientação sexual de pais gays e mães lésbicas sobre a orientação sexual de suas filhas vem recebendo atenção há algum tempo. Stacey e Biblarz (2001), por exemplo, avaliaram os resultados de 21 estudos psicológicos que foram publicados entre 1981 e 1998 sobre este tema. Segundo relataram, os 21 estudos indicam que não são encontradas diferenças com relação à orientação sexual de filhas de pais e mães homossexuais e pais e mães heterossexuais. No entanto, Stacey e Biblarz (2001) criticam esses trabalhos, pois, segundo relatam, são encontradas diferenças que poderiam ser melhor analisadas, mas essas diferenças são minimizadas, em uma tentativa de igualar as famílias formadas por homossexuais àquelas formadas por heterossexuais.

As tentativas de igualar essas famílias podem ser decorrentes da forte homofobia presente na sociedade e da heteronormatividade que regula seres sujeitos e seres abjetos, que habitam as zonas excluídas pela norma. Como refere Butler (2000) o imperativo heterossexual possibilita algumas identificações sexuadas e impede outras identificações. Haveria uma matriz excludente que produz seres que ainda não são considerados sujeitos, seres abjetos que designam as zonas "inabitáveis" da vida social, geralmente ocupadas por aquelas que não gozam do status de sujeito, mas que são necessárias para que o domínio do sujeito seja estabelecido (Butler, 2000). A partir da tentativa de igualar essas famílias, aquelas formadas por casais homossexuais poderiam ser retiradas das zonas inacessíveis.

Citamos como exemplo o estudo longitudinal de Golombok e Tasker (1996) que acompanhou filhas de mães lésbicas e mães heterossexuais ao longo dos anos. Os dados indicam que $24 \%$ das crianças criadas por mães lésbicas (6 de 25 jovens adultas) relataram ter dito uma relação homoerótica, enquanto nenhuma ( 0 de 20$)$ das crianças filhas de mães heterossexuais relataram ter tido experiências homoeróticas. Além disso, jovens adultas que foram criadas por mães lésbicas e indicaram maior propensão para experimentar atração ou relacionamento 
homoerótico configuram-se como $64 \%$ da amostra, em comparação com apenas $17 \%$ das jovens adultas filhas de mães heterossexuais. Stacey e Biblarz (2001) consideram que, a partir de tais dados, não é possível afirmar que a influência da orientação sexual dos pais e mães na orientação sexual das filhas é direta ou que é facilmente previsível, uma vez que em ambas as amostras encontramos jovens adultas com abertura para uma relação homoerótica. Entretanto, esses dados são bastante díspares, o que tornaria bastante interessante realizar uma análise mais complexa sobre eles, ao invés da simples afirmação de que não foram encontradas diferenças significativas com relação à orientação sexual dos dois grupos de jovens adultas.

Em articulação com os achados do presente estudo, podemos considerar que filhas de pais gays e mães lésbicas podem vivenciar experiências onde a norma heterossexual é menos imposta. Jéssica (38) e Carolina (42) relataram que, quando adotaram Tiago (7), o filho falava sobre os profissionais da instituição de acolhimento na qual se encontrava antes da adoção. Segundo Tiago relatava para as mães, esses profissionais falavam para as crianças da instituição que a cor azul é exclusiva dos meninos e a cor rosa, das meninas. Jéssica e Carolina buscavam desconstruir essas ideias e explicavam para o filho que meninos podem usar um anel rosa, por exemplo, e que essa divisão de cores não existe. Tereza e Manuela também falaram sobre Rafael, que costuma brincar com brinquedos considerados de meninas, não apenas aqueles considerados masculinos. Felipe também relatou:

Então algumas coisas que ela (Bia) gosta, de karatê, futebol, boneca, a mamãe diz que não é pra deixar ela brincar, eu digo mamãe ela vai brincar sim. Assim como um primo dela que brinca de boneca com ela, ela leva naturalmente, eu digo pra mamãe que ele está aprendendo a ser um bom pai. Lembrar que ele também vai poder acalentar, dar de mamar...
Cerqueira-Santos e Bourne (2015) realizaram uma investigação sobre a estereotipia de gênero durante os episódios de brincadeiras de faz de conta entre crianças adotadas por casais homossexuais masculinos. O estudo foi desenvolvido no Canadá e participaram 13 crianças, sendo oito meninos e cinco meninas, com idade entre três e sete anos. Os autores concluíram que os padrões de estereotipia de gênero encontrados são semelhantes aos estudos com crianças de pais heterossexuais. Já Stacey e Biblarz (2001) citaram que nos estudos que analisaram, as mães lésbicas se preocupam menos com as brincadeiras realizadas por suas filhas em termos de gênero, ou seja, não existe tanta preocupação como a apresentada por mães heterossexuais com relação às brincadeiras serem "de menino" ou "de menina". A partir do relato dos casais do presente estudo, as brincadeiras de suas filhas também parecem se distanciar daquelas em que há divisões relacionadas ao gênero, em que por ser um menino, a criança só pode utilizar determinados brinquedos e vice-versa. Apesar de alguns relatos trazerem que existe maior flexibilidade para que as crianças brinquem do que mais lhes agrada, não podemos afirmar que existe uma diferença entre brincadeiras realizadas por aquelas que são filhas de casais homossexuais e as que vêm de uma família heterossexual, mas é provável que exista, de fato, uma menor preocupação com relação às filhas realizarem brincadeiras consideradas corretas para a sua identidade de gênero.

Outro aspecto diz respeito a algumas entrevistadas explicarem para filhas que elas podem namorar quem desejarem, sejam meninos ou meninas.

[...] Dois homens podem viver juntos, namorar e viver juntos, duas meninas podem viver juntas. "Ah papai, mas eu não quero". Tudo bem, você pode escolher um menino, mas também se você escolher uma menina não vai ter problema, isso existe. (FELIPE).

Eu digo: quando você tiver namorado ou namorada... Então isso é dizer das 
possibilidades. Sobre a possibilidade dele ter uma namorada, o mundo inteiro já diz isso pra ele. Ele tem que saber minimamente que de alguma forma ele pode ser igual ao pai. Não to dizendo que ele tem que ser. Só quero deixar claro que ele pode ter namorado ou namorada. [...] Quando a gente fala assim ele diz "tá pai, mas eu sou hetero". Ai eu digo tá ok, mas pode ter namorada ou namorado. (ERICK).

Essas narrativas nos ajudam a pensar que a orientação sexual dos pais e das mães pode estar relacionada, ainda que não diretamente, à orientação sexual das filhas adotadas por elas, pois estas podem estar vivendo em um ambiente onde existe maior abertura e diálogo sobre as questões relacionadas a gênero e orientação sexual, o que poderia trazer para essas crianças e adolescentes maior abertura para viverem diferentes experiências, além de a homossexualidade não ser encarada como tabu ou algo proibido. A questão principal que parece se impor nessa discussão é: por que isso ainda é visto como um problema? Por que a possibilidade de essas crianças adotadas se descobrirem homossexuais é vista como danosa? Porque ainda vivemos em uma sociedade que discrimina e exclui aquelas que diferem da heteronorma. O problema que se coloca é, portanto, entrelaçado em muitos aspectos com o Estado, relacionado aos valores que regem nossa sociedade e que fazem com que inúmeras pessoas continuem discriminando e violentando pessoas LGBT. Logo, alguns pais e algumas mães se sentem temerosos quando pensam nessa possibilidade.

Um aspecto ganha destaque. Durante as entrevistas, dois casais trouxeram mais diretamente esse assunto, com um receio relacionado à possível influência que as orientações sexuais de pais e mães podem ter sobre a orientação sexual das filhas: Lucas e Rogério e Maíra e Beatriz, principalmente nas primeiras entrevistas, realizadas antes da adoção (com ambos os casais foram realizadas duas entrevistas). Os dois casais estavam vivenciando o processo de adoção ao longo de 2017 e 2018, dois anos em que foi possível observar uma crescente onda conservadora no Brasil, com a valorização de figuras políticas defensoras de ideias que excluem as famílias formadas por casais homossexuais, que se opõem às discussões relacionadas a gênero e educação sexual, além de apresentarem um discurso discriminatório e violento com relação às pessoas LGBT. Pensamento fortalecido que fez eco ao dar a vitória nas eleições presidenciais a quem externava essas ideias. Algumas declarações da referida figura política, que foi eleita como Presidente do Brasil em 2018, trazem afirmações de que meninos adotados por pessoas homossexuais serão garotos de programa, de que a união estável entre pessoas do mesmo sexo traz prejuízos para a família, para os bons costumes e para pessoas cristãs, entre tantas outras afirmações que se baseiam em crenças violentas, preconceituosas e discriminatórias ${ }^{8}$. Parece importante levar o atual cenário em consideração quando escutamos casais falarem sobre os receios de que sejam culpabilizados caso suas filhas se descubram homossexuais. Uma vez que essa figura política foi eleita, em 2018, como o Presidente do Brasil, isso nos indica que uma grande parte da população brasileira concorda com suas ideias ou não considera que esses discursos sejam maléficos e devam ser combatidos, conseguindo ignorálos, mesmo que não concordem. Como refere Coitinho-Filho (2017), a parentalidade exercida por homossexuais, no Brasil, é alvo de diversos fundamentos acusatórios que são acionados por figuras políticas e religiosas a partir da justificativa de defesa da família e da criança diante dessa parentalidade. Que família? E que criança?

$\mathrm{O}$ atual contexto brasileiro nos traz um cenário de regressão imposto pelo governo eleito em 2018, que põe em curso um programa de ataque a direitos conquistados a passos lentos e custosamente. Entre as

\footnotetext{
8 Trechos retirados da entrevista disponível no seguinte link: https://www.youtube.com/watch?v=Il 4dV4t4jY
} 
decorrências da eleição presidencial, apontamos alguns fatos que geram alerta, já no período inicial do novo governo. Entre os Ministérios que comporão o Governo brasileiro a partir de 2019, encontra-se o Ministério da Mulher, Família e Direitos Humanos (antes Ministério dos Direitos Humanos), que tem como responsáveis uma Ministra e um Secretário-Executivo que já proferiram, publicamente, discursos contrários às diversas expressões de gênero e à união entre pessoas do mesmo sexo. A inclusão do nome "família" ao Ministério também chama a atenção, pois a ideia de família defendida pelo governo eleito é unicamente relacionada às uniões entre homens e mulheres, o que deixa clara a intenção de associar direitos humanos a certo tipo de família, considerada como a única aceitável. Além disso, os discursos citados acima, proferidos por figuras que estão à frente de um Ministério dos Direitos Humanos e que deveria garantir os direitos da população LGBT, indicam que as articulações que vêm sendo feitas pelo atual governo não visam à garantia dos direitos já conquistados pela população LGBT, assim como também se torna difícil vislumbrar qualquer avanço na conquista desses direitos.

Algumas entrevistadas trouxeram narrativas que nos indicam que a maior naturalização de comportamentos discriminatórios e violentos contra a população LGBT não está passando despercebido por elas.

Olha, eu não sei se é porque ainda não era o tempo do [presidente eleito em 2018] sabe? Porque a gente tá perdendo né? A gente ta perdendo o pudor, né? Esse tempo bolsominion, tá cada vez mais naturalizado o preconceito, as fobias sociais contra as minorias sociais, estamos perdendo o pudor. (RAFAELA).

E isso volta mais fortemente agora, as pessoas tão mais vorazes, o politicamente incorreto virou besteira, antes as pessoas tinham isso de não poder ser racista, não poder ser machista, não poder ser homofóbico na fala e agora não, as pessoas postam no facebook, falam publicamente... É um movimento reacionário, porque a gente avançou muito. Como a gente avançou muito o conservadorismo veio com força pra reagir a esse avanço, entendeu? (ERICK).

Hoje em dia as pessoas estão cada vez mais fechadas nos seus mundos... Eu não me sinto a vontade, por exemplo, de andar de mãos dadas num shopping. Acho desnecessário correr o risco. Não é o andar de mãos dadas, é o risco. Ainda mais num tempo de [citou o Presidente eleito]. Difundido pelo país, essas pessoas acham que tudo que você faz. é uma ofensa e acham que tem liberdade pra lhe oprimir de qualquer jeito. Então... (JÉSSICA).

Maíra também trouxe, em sua narrativa, uma referência ao momento político vivenciado no Brasil, explicando que: "Eu até brinco, minha única apreensão é que o [citou o Presidente Eleito em 2018] não seja eleito antes que minha guarda saia, porque é capaz dele mudar a Lei pra eu não poder adotar meus filhos". Posteriormente à entrevista, o casal comunicou que conseguiu a guarda definitiva de Gabriel e Diego no começo de dezembro de 2018.

É interessante observar que algumas pessoas que participaram dessa pesquisa apresentam o receio semelhante àquelas que participaram do estudo de Dantas e Ferreira, citado anteriormente, apesar de a entrevista descrita no estudo acima datar de 2008, ou seja, alguns anos atrás. Isso nos permite refletir que, apesar de mudanças, debates, conquistas e algumas aberturas para a constituição de famílias que fogem aos modelos hegemônicos, receios, temores e constrangimentos ainda rondam as vidas daquelas que vão contra o instituído 
socialmente. Isso nos mostra a permanência de uma visão sobre essas famílias: a de que são desviantes e anormais. Assumir-se homossexual e decidir que, apesar disso, é possível ser pai e mãe, pode ser visto como ato ousado em nossa sociedade.

De Garay Hernández (2013) afirma que é importante que nos distanciemos de uma perspectiva adultocêntrica, a partir da qual as crianças são compreendidas como sujeitos passivos, para uma perspectiva que as considere como sujeitos ativos que participam dos processos em que estão envolvidas, sejam processos culturais ou sociais. Como afirma a autora "A infância não se define de forma cronológica, mas em termos de potência, de afetos, de busca de possibilidades de existência e re-existência" (De Garay Hernández, 2013, p. 85). Isso nos permite olhar para as crianças como seres potentes e ativos, que podem encontrar significados para suas experiências de vida e não são apenas influenciados pela orientação sexual de seus pais e de suas mães.

Um argumento geralmente utilizado nas discussões e debates sobre a influência ou não da orientação sexual de pais e mães homossexuais sobre suas filhas diz respeito às narrativas que afirmam que a maioria das pessoas homossexuais cresceu em famílias heteroparentais, o que poderia indicar que a orientação sexual das mães e dos pais não definiria a orientação sexual das filhas. De Garay Hernández (2013) afirma que este argumento também nos mostra a heteronormatividade que impera em nossa sociedade, na medida em que coloca a homossexualidade, mais uma vez, como indesejada, anormal, algo que deve ser evitado nas crianças.

Outra questão também se sobressai. Algumas das nossas entrevistadas referem-se ao medo de que recaia sobre elas a culpa pela possível homossexualidade das crianças adotadas. Parece haver, portanto, dois temores, que caminham em paralelo e se entrelaçam em diversos momentos: aquele referente a essas crianças e jovens se descobrirem homossexuais e o receio que diz respeito à culpa que pode ser depositada sobre seus pais e suas mães. Na medida em que não gostariam de ser responsabilizadas pela homossexualidade da filha adotada, nos trazem elementos sobre a forma pela qual a homofobia atuante na sociedade as atravessa, produzindo o receio de que suas filhas sofram discriminações e violências caso se descubram homossexuais e de que sobre elas seja depositada essa culpa. Esses receios podem ser articulados às construções sociais que ainda marcam os discursos vigentes e impõem que a heterossexualidade se configura como a forma correta de viver a sexualidade.

Diante da possibilidade da culpabilização, esses casais buscam maneiras de pensar que, apesar de suas orientações sexuais, suas filhas poderão vivenciar suas sexualidades como desejarem, sem que seja imposto para elas qual seria uma orientação sexual correta ou natural. Como nos lembra De Garay Hernández (2013) a expressão da sexualidade é diversa e flexível e não se limita à noção de orientação sexual, que pode, inclusive, ser desconstruída, pois não é fixa, sendo possível escapar do binômio normal/desviante. As novas gerações parecem não se sentir impelidas a "decidir seus desejos por uma orientação que as fixe em determinado lugar de inteligibilidade que as limitem. Parecem operar muito mais pelo desejo, oportunidade, deslizamento, do que por orientação sexual" (De Garay Hernández, 2013, p. 88). Ao que podemos considerar mais importante, nossas entrevistadas se mostram dispostas: não fazer imposições e aprender a serem pais e mães. Vale considerar também o que traz Zambrano (2008), que explica que a socialização de filhas em ambientes com famílias de pessoas do mesmo sexo permite que as crianças transitem melhor entre as diversas possibilidades de relações afetivosexuais.

Como discutimos acima, é difícil afirmar que existe uma relação direta entre a orientação sexual dos pais, mães e das filhas, e este não se apresentou como nosso objetivo. Mas parece importante que esses debates e 
discussões não sejam postos de lado com o objetivo de que as possíveis diferenças sejam minimizadas, mesmo que com isso se busque menores estigmatizações para essas famílias que fogem ao modelo hegemônico. Essas famílias são certamente atravessadas pelo que a sociedade ainda concebe como grande e importante diferença. $\mathrm{O}$ mais importante parece ser a desconstrução dessa possível relação como algo negativo para filhas de casais homossexuais, para que a diferença passe a ser encarada apenas como diferença.

\section{Considerações finais}

Famílias formadas por casais homossexuais, com filhas ou não, sejam essas filhas adotadas ou geradas por meio de tecnologias reprodutivas, ou vindas de relações heterossexuais anteriores, são famílias que estão inseridas em uma sociedade atravessada por ideias e paradigmas que se organizam a partir de uma heteronorma. Podemos tentar inferir que, por se constituírem como famílias que fogem ao modelo hegemônico imposto socialmente, seriam famílias que se oporiam e divergiriam das imposições derivadas da heteronormatividade. No entanto, facilmente descobriremos que estamos equivocadas. Uma vez que estão inseridas em uma sociedade que se organiza dessa maneira, tecem articulações com esse modelo de organização familiar e se distanciem e se aproximem em alguns aspectos.

Como trazem De Garay Hernández, Silva e Uziel (2013) as produções da academia e dos movimentos sociais podem convidar essas famílias a questionamentos, mas não trazer imposição sobre como esses sujeitos devem se comportar ou construir suas relações familiares e parentais.

No entanto, ressaltamos que não pretendemos sugerir que as famílias de pais gays e mães lésbicas devam ser as únicas ou as primeiras a questionar esses significados (divisões de gênero, violência, maternidade), já que, fazendo parte dessa cultura, mães lésbicas e sua prole relacionaram-se intimamente com esses e moldaram suas linhas de vida a partir deles. A transgressão às normas não é algo inerente à orientação sexual, mas uma escolha política (De Garay Hernández \& Caetano, 2015, p. 125-126).

Concordamos com essas considerações e propomos que essas famílias, ao narrarem suas experiências e nos mostrarem o encontro com a heteronormatividade no exercício de suas parentalidades, estão nos possibilitando a produção de tensões e questionamentos, estão nos propondo que percebamos que não é por se relacionarem afetivo-sexualmente com pessoas do mesmo sexo que esses sujeitos devem ser transgressores de toda e qualquer norma social. Surgem, então, desconstruções possíveis, considerando que essas famílias não são homogêneas, possuem vivências que apresentam semelhanças e diferenças, escolhem maneiras de exercer a parentalidade que diferem entre si, pois são também singulares.

A compreensão de que a família é uma construção sociocultural dinâmica, flexível, plástica e capaz de incorporar cada vez mais formas de manifestação de vínculos sexuais e afetivos entre seres humanos torna possível pensá-la não como algo natural e estático, mas, sim, como uma organização complexa e com direito a uma diversidade rica e crescente (De Garay Hernández, Silva, \& Uziel, 2013, p. 375).

Essas famílias se apresentam, portanto, como sendo atravessadas por alguns elementos que não se distanciam tanto de modelos familiares heterossexuais, que também são diversos, mas, ao mesmo tempo, não seguem um modelo único e pré-definido, estando abertas para sua construção em um movimento de parceria com suas companheiras e com as crianças que chegaram. As narrativas que se mesclam se encontram e se desencontram 
nesse trabalho falam de uma multiplicidade, de variedades e de possibilidades distintas de construções de famílias e parentalidades. Foram construídas com aquelas que se dispuseram a falar de suas vidas e experiências, que afetaram e foram afetadas durante as intervenções realizadas e que colaboraram para esse pequeno fragmento de resistência.

\section{Referências}

Butler, J. (2000). Corpos que pensam: sobre os limites discursivos do sexo. In G. L. Louro (Org.), Corpo educado: pedagogias da sexualidade (pp. 110-125). Belo Horizonte: Autêntica.

Butler, J. (2003). O parentesco é sempre tido como heterossexual? Cadernos Pagu, (21), 219-160. doi: 10.1590/S010483332003000200010

Cerqueira-Santos, E., \& Santana, G. (2015). Adoção homoparental e preconceito: crenças de estudantes de direito e serviço social. Temas em Psicologia, 23(4), 873885. doi: 10.9788/TP2015.4-06

Coitinho-Filho, R. A. (2017). Sob o "melhor interesse"! O "homoafetivo" e a criança nos processos de adoção. Estudos Feministas, 25(2), 495-518. doi: 10.1590/18069584.2017v25n2p495

Coitinho-Filho, R. A., \& Rinaldi, A. A. (2015). A "homoafetividade" no cenário adotivo: um debate antropológico. Mediações, 20(1), 285-306. doi: 10.5433/2176-6665.2015v20n1p285

Dantas, F. S. S., \& Ferreira, S. P. A. (2015). Adoção tardia: produção de sentidos acerca da paternagem e filiação em uma família homoafetiva. Temas em Psicologia, 23(3), 593-606. doi: 10.9788/TP2015.3-06

De Garay Hernández, J. (2013). Filhas de famílias homoparentais: processos, confrontos e pluralidades (Dissertação de Mestrado). Instituto de Psicologia, Universidade do Estado do Rio de Janeiro, Rio de Janeiro.

De Garay Hernández, J., \& Caetano, M. (2015). Hijas de familias lesboparentales: articulaciones desde una mirada feminista crítica. Revista entramados y perspectivas, 5, 113-134. Recuperado de https://publicaciones.sociales.uba.ar/index. php/entramadosyperspectivas/article/view/1 $\underline{497}$
De Garay Hernández, J., Silva, D. A., \& Uziel, A. P. (2013). A luta pelo amor e o amor pela luta: notas sobre a cerimônia coletiva de uniões homoafetivas no Rio de Janeiro. Sociedade e Cultura (Online), 15, 369-377. doi: $10.5216 / \mathrm{sec} . v 15 i 2.22404$

Golombok, S., \& Tasker, F. (1996). Do parents influence the sexual srientation of their children? Findings from a longitudinal study of lesbian families. Developmental Psychology, 32(1), 3-11. doi: 10.1037/0012-1649.32.1.3

Junqueira, R. D. (2012). Homofobia: limites e possibilidades de um conceito em meio a disputas. Bagoas - estudos gays: gênero e sexualidade, 1(1), 01-22. Recuperado de https://periodicos.ufrn.br/bagoas/article/vie w/2256/1689

Meletti, A. T., \& Scorsonolini-Comin, F. (2015). Conjugalidade e expectativas em relação à parentalidade em casais homossexuais. Psicologia: Teoria e Prática, 17(1), 37-49. doi: 10.15348/19806906/psicologia.v17n1p37-49

Moraes, M. (2010). PesquisarCOM: política ontológica e deficiência visual. In M. Moraes, \& V. Kastrup. Exercícios de ver e não ver: arte e pesquisa com pessoas com deficiência visual (pp. 26-51). Rio de Janeiro: Nau Editora.

Silva, D. A., Uziel, A. P., \& De Garay Hernández, J. (2013). Esta é uma casa de família! A homoparentalidade sob o olhar de duas diferentes gerações. Población, (10), 47-58. Recuperado de http://www.mininterior.gov.ar/poblacion/pd f/poblacion_10.pdf

Stacey, J., \& Biblarz, T. (2001). (How) Does the sexual orientation of parents matter? American Sociological Review [online],66(2), 159-183. doi: $\underline{10.2307 / 2657413}$ 
Tedesco, S. H., Sade, C., \& Caliman, L. V. (2013). A entrevista na pesquisa cartográfica: a experiência do dizer. Fractal: Revista de Psicologia, 25(2), 299322. doi: $10.1590 /$ S198402922013000200006

Uziel, A. P. (2007). Homossexualidade e adoção. Rio de Janeiro: Garamond.

Vilhena, J., Souza, A. C. B., Uziel, A. P., Zamora, M. H., \& Novaes, J. V. (2011). Que Família? Provocações a partir da
Homoparentalidade. Revista Mal-estar e

Subjetividade, 11(4),1639-1658.

Recuperado de:

http://pepsic.bvsalud.org/pdf/malestar/v11n 4/14.pdf

Zambrano, E. (2008). "Nós também somos familia”: Estudo sobre a parentalidade homossexual, travesti e transexual (Tese de doutorado). Instituto de Filosofia e Ciências Humanas, Universidade Federal do Rio Grande do Sul, Rio Grande do Sul.

\section{Dados sobre as autoras:}

- Lívia Lima Gurgel: Graduada em Psicologia pela Universidade Federal do Ceará (2017). Mestra em Psicologia Social, pelo Programa de Pós-Graduação em Psicologia Social da Universidade do Estado do Rio de Janeiro (2019). Tem experiência na área de Psicologia Social, atuando principalmente nos seguintes temas: famílias, homoparentalidade, gênero e sexualidade. Pesquisadora do Grupo de Estudos e Pesquisas Subjetividades e Instituições em Dobras (GEPSID), da Universidade do Estado do Rio de Janeiro.

- Anna Paula Uziel: Possui graduação em Filosofia pela Universidade Federal do Rio de Janeiro (1988), graduação em Psicologia pela Universidade do Estado do Rio de Janeiro (1991), mestrado em Psicologia (Psicologia Clínica) pela Pontifícia Universidade Católica do Rio de Janeiro (1996) e doutorado em Ciências Sociais pela Universidade Estadual de Campinas (2002). É professora associada da Universidade do Estado do Rio de Janeiro, coordenadora do LIDIS - Laboratório Integrado em Diversidade Sexual e de Gênero, Políticas e Direitos e pesquisadora associada do Centro Latino-Americano em Sexualidade e Direitos Humanos (CLAM/IMS/UERJ). Já foi coordenadora do Programa de Pós-Graduação em Psicologia Social (PPGPS) em dois mandatos. Seus principais campos de interesse são Psicologia Jurídica e Sexualidade.

\section{Agradecimentos:}

À Coordenação de Aperfeiçoamento de Pessoal de Nível Superior (CAPES) pela concessão de bolsa de mestrado ao longo do desenvolvimento da pesquisa apresentada no artigo. 